\title{
Psychosocial Assessment and Care
}

National Cancer Institute

\section{Source}

National Cancer Institute. Psychosocial Assessment and Care. NCI Thesaurus. Code C15514.

The act of determining, usually through interviews and observation, the state of an individual's psychological state and social environment, and subsequently providing assistance to the individual based on their needs. 